https://doi.org/10.12657/folmal.028.010

\title{
A CONICAL NEW SPECIES OF PUPOPSIS GREDLER, 1898 FROM CHINA (GASTROPODA: STYLOMMATOPHORA: ENIDAE)
}

\author{
ZHE-YU CHEN \\ College of Food Science and Engineering, Wuhan Polytechnic University, No. 68 XueFu South Road, \\ Dongxihu District, 430023 Wuhan, P.R. China (e-mail: chenzheyu1998@163.com); \\ (1) https://orcid.org/0000-0002-4150-8906
}

\begin{abstract}
A new enid species, Pupopsis huangi sp. nov. is described from northwest Sichuan (China) based on its conical shell and apertural barriers; it is the fifteenth species of the genus in China. Illustrations of the new species are provided.
\end{abstract}

KEY WORDS: shell morphology, systematic, new species, Sichuan

\section{INTRODUCTION}

Chinese enid species have been well studied by previous researchers (WU \& WU 2009, WU \& ZHENG 2009, WU \& GAO 2010, WU \& XU 2013, WU 2018). Among them Pupopsis Gredler, 1898 is the only genus with complex apertural barriers in the region. As defined by WU \& GAO (2010) and WU (2018), Pupopsis has solid and elongate ovate shell; angular tubercle strongly developed; 0-4 apertural barriers: one parietal plica, one columellar lamella present or absent, 1-2 palatal plicae present or absent (lower palatal plica, when present, can be ridge-like and can extend inward up to an entire whorl); umbilicus minute, cylindrical or slit-like. This genus is known from SE. Gansu, N. Sichuan and NW. Xinjiang (WU \& GAO 2010, Wu 2018).

A new species, Pupopsis huangi sp. nov., was recognised among terrestrial molluscs collected by Mr. Bo Huang from Wenchuan, Sichuan. Its unique shell shape distinguishes it from any other known Pupopsis.

\section{MATERIAL AND METHODS}

Observations and measurements were performed using an AmScope SF-2TRA stereo zoom microscope. The shells were measured with a digital vernier calliper to the nearest $0.1 \mathrm{~mm}$. Whorls were counted as described by KERNEY \& CAMERON (1979). Photographs of the shell were taken using a
Canon 5D Mark IV camera and modified in Adobe Photoshop CC 2018.

Abbreviation: HBUMM - mollusc collection of the Museum of Hebei University (Baoding, Hebei, China); HBc - Collection BO HUANG (Lanzhou, Gansu, China). 


\section{TAXONOMY}

\section{Family Enidae Woodard, 1903}

\section{Genus Pupopsis Gredler, 1898}

Type species: Buliminus pupopsis Gredler, 1898, by original designation.

Pupopsis huangi sp. nov.

(Figs 1-4)

Type material. China, Sichuan Province, Tibetan Qiang Autonomous Prefecture of Ngawa [阿坝藏族差 族自治州], Wenchuan County [汶川县], $31^{\circ} 28.92 ' \mathrm{~N}$, $103^{\circ} 35.22^{\prime}$ E, alt. 1,300 m a.s.l., leg. BO HUANG, 2019Jun-3. HBUMM 10027 spec.1 (empty shell, shell height $-5.8 \mathrm{~mm}$, shell width $-4.5 \mathrm{~mm}$ ) holotype;
Paratypes: HBUMM 10027 spec. 2-5 (3 complete empty shells and one broken shell with only body whorl preserved), $\mathrm{HBc} / 1$ (empty shell).

Measurements. Shell height $-5.7-6.0 \mathrm{~mm}$, shell width - 4.4-4.7 $\mathrm{mm}(\mathrm{n}=4)$.

Description. Shell small, dextral, light-brownish, oblong-conical, of 5.5-5.75 convex and regularly increasing whorls (Fig. 1); protoconch consists of 1.5-1.75 matt whorls, without characteristic microsculpture; teleoconch gradually widening, with dense growth lines, more pronounced in the region of umbilicus; suture impressed; aperture nearly oval; peristome strongly expanded, partly detached from the body whorl; callus elevated or not; angular tubercle strongly developed; apertural barriers (Figs 2-3)

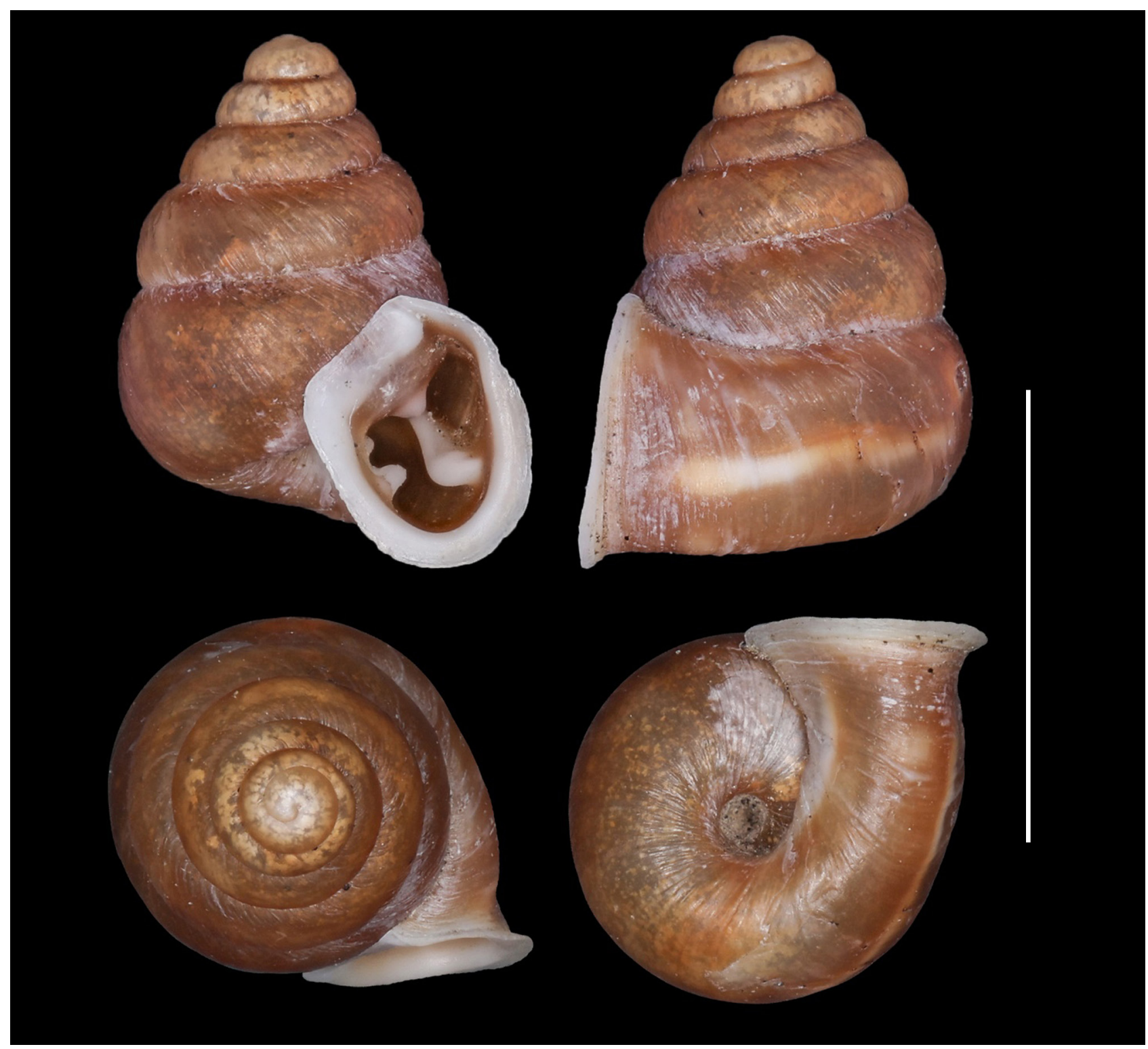

Fig. 1. Pupopsis huangi sp. nov., HBUMM 10027 spec. 1, holotype. Scale bar 5 mm. Photo: ZHE-YU CHEN 


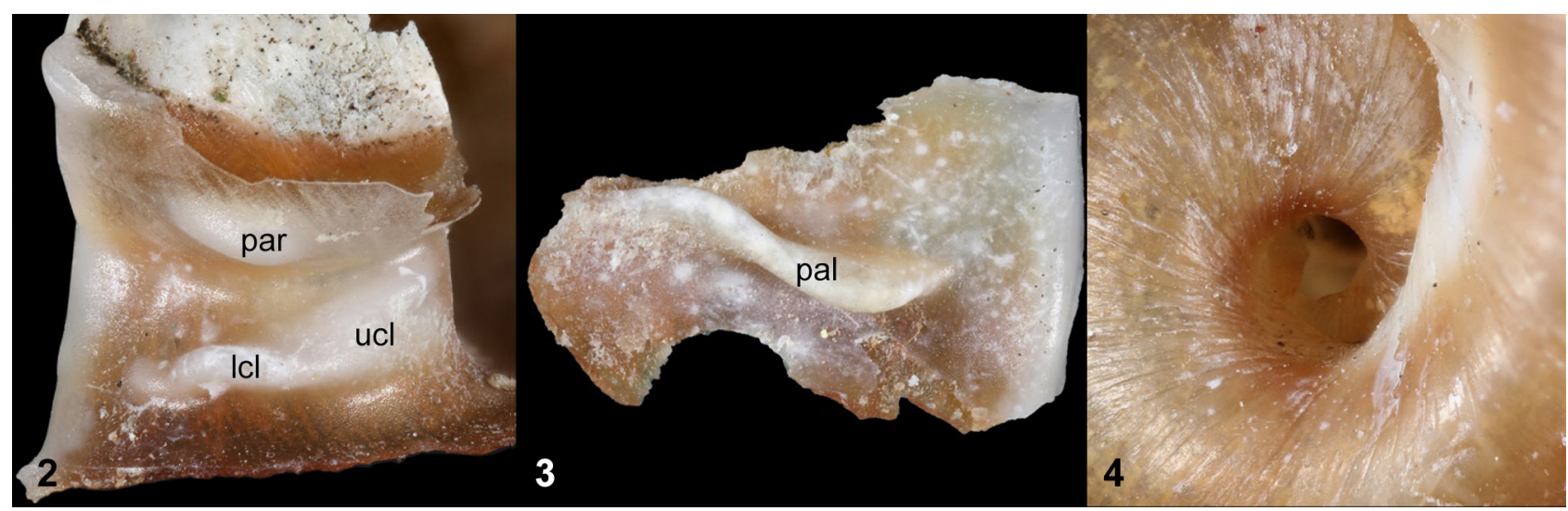

Figs 2-4. Pupopsis huangi sp. nov.: 2-3 - apertural barriers, 4 - umbilical area. Abbreviations: lcl - lower columellar lamella, pal - palatal plica, par - parietal plica, ucl - upper columellar lamella. Photo: ZHE-YU CHEN

do not reach the peristome; one parietal plica present, colliculus; one palatal plica present, roughly parallel with the suture, anterior end strongly developed, slightly bent downward, posterior end weaker than the anterior, extending inward to the dorsal side; two columellar lamellae present, parallel but situated at different depth; lower columellar lamella, shallow and strong, opposite to the top of palatal plica; upper columellar lamella deep-set, weaker than the lower; anterior end of lower columellar lamella and posterior end of upper columellar lamella in the same vertical plane; these two parts are connected by a thickening in some specimens; umbilicus open, cavernous (Fig. 4).

Remarks. The new species can be placed in Pupopsis based on its angular tubercle and identical apertural barriers, namely including a parietal plica and an extremely long palatal plica. As all the known species in the genus are pupoid-shaped, the new species is distinguishable from its congeners by the conical shell, the widely opened umbilicus and the double colu-

\section{REFERENCES}

GREDLER V. 1898. Zur Conchylien-Fauna von China. XIX. Stück. Neue Buliminiden aus Kansu. Programm des öffentlichen Privat-Obergymnasiums der Franciscaner zu Bozen 1897-98: 39-51.

Kerney M. P., CAmeron R. A. D. 1979. A field guide to the land snails of Britain and North-west Europe. Collins, London.

WU M. 2018. Fauna Sinica: Invertebrata Vol. 58 (Mollusca: Gastropoda: Enoidea). Science Press, Beijing.

WU M., WU Q. 2009. A study of the type species of Clausiliopsis Möllendorff (Gastropoda, Stylommatophora: Enidae), with the description of a new species. Journal of Conchology 40: 91-98.

Wu M., ZHENG W. 2009. A review of Chinese Pupinidius Moellendorff (Gastropoda, Stylommatophora: Enidae), mellar lamellae. The above characteristics expand the diagnosis of Pupopsis.

Etymology. The specific epithet is dedicated to Mr. BO HUANG, the collector of this new species.

Type locality. China, Sichuan Province, Tibetan Qiang Autonomous Prefecture of Ngawa [阿坝藏族羌 族自治州], Wenchuan County [汶川县], $31^{\circ} 28.92 ' \mathrm{~N}$, 10335.22'E, alt. 1,300 m a.s.l.

Distribution. This species is known from the type locality only.

Vernacular name. 黄氏蛹纳螺

\section{ACKNOWLEDGEMENT}

I thank Mr. Bo HUANG (Lanzhou, Gansu, China) for providing the type material, to Dr. BARNA PÁLLGERGELY for his advice regarding research and to the two anonymous reviewers for their helpful comments on the manuscript. This study was funded by the National Natural Science Foundation of China (NSFC 31872196).

with the description of a new species. Zootaxa 2053: 1-31. https://doi.org/10.11646/zootaxa.2053.1.1

WU M., GaO L.-H. 2010. A review of the genus Pupopsis Gredler, 1898 (Gastropoda: Stylommatophora: Enidae), with the descriptions of eight new species from China. Zootaxa 2725: 1-27. https://doi.org/10.11646/zootaxa.2725.1.1

WU M., XU Q. 2013. Serina Gredler (Gastropoda, Stylommatophora: Enidae), the continuous-peristomed mountain snails endemic to the eastern slope of the Qinghai-Xizang Plateau. Zootaxa 3620: 43-66. https://doi.org/10.11646/zootaxa.3620.1.2

Received: March 2nd, 2020 Revised: March 30th, 2020 Accepted: April 4th, 2020 Published on-line: May 19th, 2020 